\title{
Optimal harvesting of stochastic spatial resources
}

\author{
Christopher Costello ${ }^{\mathrm{a}, *}$, Stephen Polasky ${ }^{\mathrm{b}}$ \\ ${ }^{a}$ Donald Bren School of Environmental Science and Management, Department of Economics, \\ 4410 Bren Hall, Santa Barbara, CA 93117, USA \\ ${ }^{\mathrm{b}}$ Department of Applied Economics, University of Minnesota, USA \\ Received 7 July 2006 \\ Available online 8 March 2008
}

\begin{abstract}
We characterize the optimal harvest of a renewable resource in a generalized stochastic spatially explicit model. Despite the complexity of the model, we are able to obtain sharp analytical results. We find that the optimal harvest rule in general depends upon dispersal patterns of the resource across space, and only in special circumstances do we find a modified golden rule of growth that is independent of dispersal patterns. We also find that the optimal harvest rule may include closure of some areas to harvest, either on a temporary or permanent basis (biological reserves). Reserves alone cannot correct open access, but may, under sufficient spatial heterogeneity and connectivity, increase profits if appropriate harvest controls are in place outside of reserves.
\end{abstract}

(C) 2008 Elsevier Inc. All rights reserved.

Keywords: Marine reserves; Spatial externalities; Stochastic dynamic programming; Renewable resources; Bioeconomic modeling

\section{Introduction}

Analysis of the spatial distribution of economic activity has increased significantly in recent years. Prominent applications include the spatial dimensions of international trade and regional development [14], locational equilibrium in urban growth [12], environmental policy [16], and natural resource extraction $[28,39,15]$. These applications have emerged from the realization that resources and economic opportunities are distributed heterogeneously across space, giving rise to issues of transportation, locational choice, and trade. In addition to exhibiting spatial heterogeneity, many biological resources move across space, thus connecting actions in one place to future economic opportunities in other places. Optimal harvesting rules are therefore connected across space and time, leading to potentially complex optimization problems. In addition, renewable resources are often subject to considerable uncertainty and variability driven by environmental stochasticity $[37,43]$.

In this paper, we characterize optimal harvesting of a renewable resource in a stochastic spatial model, capturing both spatial heterogeneity and connectivity. Spatial heterogeneity can arise from economic factors (e.g. differences in harvest costs or transportation costs) or from biological factors (e.g. differential

*Corresponding author. Fax: + 18058937612 .

E-mail address: Costello@bren.ucsb.edu (C. Costello). 
productivity from underlying environmental differences). While spatial heterogeneity and connectivity are ubiquitous in the real world, and spatial ecology has become a fairly well-developed field [48], spatial issues have only recently garnered much attention in resource economics. Spatial models of resource harvest include seminal contributions by Clark [5], Brown and Roughgarden [2], and Sanchirico and Wilen [39]; we review this literature in Section 1.

Our model is a general renewable resource model with stochastic biological growth and an arbitrary number of heterogeneous resource production sites (called "patches"). We allow for stochastic growth of the resource within each patch and stochastic dispersal of the resource between patches. Economic variables can also be spatially heterogeneous. Solving this model involves stochastic spatial dynamic optimization with arbitrary spatial heterogeneity and arbitrary spatial externalities. Despite model complexity we obtain sharp analytical results and show how existing economic theories fall out as special cases.

Within this framework we characterize the optimal spatially explicit harvesting strategy that maximizes the expected present value of profit from harvest. We divide our analysis into cases with interior solutions, in which it is optimal to harvest a positive amount of stock from each patch in each period, and cases with corner solutions, where it is optimal to close at least some patches in some periods. With fully interior solutions, we show that the optimal strategy will in general vary across space but be time and state independent. In special circumstances where harvest costs and survival are linear and identical across patches, the optimal harvest rule satisfies a "golden rule of growth" in each patch and is independent of dispersal.

By analyzing corner solutions, our approach allows us to examine an important policy question regarding spatial resource use, namely whether it is economically optimal to close some areas to harvest (i.e., establish biological reserves). That establishing biological reserves can increase the overall profitability of harvest does not immediately accord with economic intuition. However, we find that spatial connections through dispersal along with spatial heterogeneity can generate cases where it is optimal to establish biological reserves. We demonstrate that having reserves also affects the optimal harvesting strategy in non-closed areas. We show that it is optimal to decrease harvest in non-closed areas that connect to reserves (via dispersal) when it is in fact optimal to establish a reserve. On the other hand, if some areas are arbitrarily closed, then the optimal policy in non-closed areas is to increase harvest.

We also analyze the consequences of changes in stochasticity on the optimality of closing patches to harvest, the optimal harvest levels outside of closed patches, and the expected value of harvest. Increasing variability in biological parameters tends to make temporary closures optimal but makes optimal permanent closures unlikely. The effect of an increase in variability of biological parameters on expected returns from harvest depends to a great extent on whether increases in variability primarily affect stocks in closed patches or open patches.

Our focal resource is the fishery which is well characterized by spatial connectivity (larval dispersal across space) and heterogeneity (sites of differing harvest costs or biological productivity). Fisheries are also subject to significant interannual variability - both in life history stages and in the dispersal process itself. In addition to fisheries problems, the theory developed here is applicable to other renewable resources (e.g. forest products) as well as important policy issues that share many formal similarities with renewable resources (e.g. antibiotic or pesticide resistance).

\section{Background}

Fifty years ago, scientists were beginning to recognize that many renewable resources, once plentiful and seemingly limitless, were in decline; stocks were diminishing and increasing amounts of effort were required to maintain harvest levels. At the time, biologists played the leading role in policy design and analysis; primarily focused on fisheries. Only later would economists engage in this discussion and convincingly articulate the role economic behavior played in the problem, and the potential role economic institutions could play in the solution $[17,42]$. As Gordon explained

Owing to the lack of theoretical economic research, biologists have been forced to extend the scope of their own thought into the economic sphere and in some cases have penetrated quite deeply, despite the lack of the analytical tools of economic theory [17]. 
The seminal works of Gordon [17] and Scott [42] spawned an immense economics literature more or less devoted to examining the institutional failures inherent in competitive resource extraction. Gordon [17] illuminated the externality of one harvester on others, while Scott [42] was the first to note the dynamic nature of the problem through the effect of harvest on future stocks. When combined with a reasonable depiction of economic harvesting behavior, these observations pointed out the "tragedy of open access". In the absence of certain kinds of institutions, rents would be completely dissipated and the value of the fishery driven to zero. Subsequent works by Crutchfield and Zellner [10], Smith [44,45], Clark and Munro [6], and others examined this dynamic interplay in detail, and outlined a number of possible institutional corrections, which, it was thought, could help secure rents in perpetuity. The subsequent literature on bioeconomics examined a number of extensions to the basic model including rational expectations [1], environmental variability [36], overcapitalization [19], political economy [27], and others. ${ }^{1}$

Five decades hence, despite countless subsequent contributions by economists, many renewable resources are-by any performance measure - patently worse-off than they were in the 1950s [52,33,25]. And just as Gordon observed in 1954, biologists are playing policy analysts, and are, in fact, leading inquiry about the linkages between scientific insights and the design of institutions for managing these systems. As before, most of the analysis by biologists on this issue takes little account of economic behavior, incentives, and objectives.

Spatial connectivity of the bioeconomic environment - driven by the interplay between environmental, biological, and economic conditions - imposes an important spatial externality that remains largely ignored in economic analysis but is perhaps as significant a cause of mis-allocation of resources as the dynamic externality identified five decades ago. Spatial externalities arise whenever economic activity in one location influences returns in another location. If fish larvae drift, animals migrate, seeds disperse, water tables recede, or pests intermingle, then optimal spatial activity may differ from that which arises from the decentralized private property solution. In fisheries, inefficiency from migration of fish stocks across management boundaries has been investigated by Clarke and Munro [7], Ferrara and Missios [13], Munro [31,32], Missios and Plourde [30], Naito and Polasky [34], and others.

Would accounting for these complex dynamical and often stochastic spatial linkages appreciably change, in a qualitative way, the conclusions about optimal economic exploitation of natural resources? That is the focus of this paper.

To our knowledge the first substantive attempt to link spatial relationships in a true bioeconomic model is given by Clark [5], which explores both open access and optimal harvest in a model where spatial connections are driven by diffusion. Brown and Roughgarden [2] were the first to examine a metapopulation model in an economic optimization framework. They assume uniform connectivity across space instead of diffusion. Assuming diffusion along a line or uniform connectivity reduces the consequences of spatial linkages and thus limits the scope of economic questions that can be addressed. Sanchirico and Wilen [39] analyze a metapopulation model similar to Brown and Roughgarden [2] but do so in a discrete patchy environment. This framework allows them to develop a more general model of spatial connectivity.

Holland and Brazee [24] appears to be the first systematic exploration of the economics of marine reserves, and has paved the way for models with more economic generality. Using the model of the discrete patchy environment, Sanchirico and Wilen [40] examine the consequences of establishing a reserve in the absence of any regulation in the harvest region. Open access outside the reserve drives rents to zero, so the authors examine the consequences of reserve creation on total harvest.

But given our interest in optimal spatial exploitation, the literature that focuses on open access conditions outside reserves provides little guidance. Some progress has been made on the question of optimal harvesting with reserves using a mix of 2-patch examples, specific functional forms, and simulation. Economists have partially analyzed the economic consequences of marine reserves on fisheries profits. Conrad [8] and Hannesson [20] reach pessimistic conclusions about the ability of reserves to increase profitability while Sanchirico et al. [38] find that reserves can increase profits. Grafton et al. [18] show that reserves can make a system more resilient following a discrete negative shock to the ecosystem. Smith and Wilen [46] examine the economic implications of closing a patch to fishing, paying particular attention to fishermens' decisions about

\footnotetext{
${ }^{1}$ Wilen [50] provides an informative and thorough chronology of the contributions of economists to institutional policy design for natural resources.
} 
whether and where to fish. They find that taking these spatial decisions into account can significantly diminish the attractiveness of area closures. Neubert [35] develops a similar model in continuous space and builds an argument for an infinite number of infinitesimally small reserves.

We are aware of only one paper that examines optimal spatial exploitation in a generalized connected and patchy environment. Sanchirico and Wilen [41] analyze the question by examining the case of "regulated open access" in which the fishery manager can choose spatially heterogeneous landings and effort taxes in a deterministic environment. In that model the objective is linear in these control variables and so a bang-bang solution is obtained. Focus is devoted to the singular control that obtains in the equilibrium. The scope of that paper is limited to interior solutions which leaves unanswered the question of whether harvest closures can ever be a part of a spatial optimized harvest regime.

Our paper generalizes and contributes to the existing literature along three important dimensions. First, we analyze optimal spatial harvest in a general model that accounts for the possibility of patch closures. Second, we solve for the optimal harvest dynamics that account for spatial externalities. Finally, we generalize our results to a stochastic setting.

\section{A simple example}

Much of the intuition for our main results can be gleaned from a simple two-patch example. Suppose a single fisherman, whose goal is to maximize the present value of profit from fishing, has control over a closed system consisting of two patches, $A$ and $B$. For this example, assume harvest cost is linear in harvest and price is constant so that profit is linear in harvest. With these assumptions, the optimal harvest plan, which maximizes the present value of profit, is one that maximizes the present value of harvest volume. Harvesting takes place in discrete periods and let $\delta$ be the discount factor between periods: $\delta=1 /(1+r)$, where $r$ is the discount rate. Define $x_{i t}$ as the fish stock in patch $i$ at the beginning of period $t$, and $h_{i t}$ as the harvest in patch $i$, in period $t, i=A, B, t=0,1,2 \ldots$. The fish stock in patch $i$ at the end of period $t$ after harvest (called "escapement") is $e_{i t}$. The escapement can be linked to beginning-of-period stock and harvest through the identity: $e_{i t} \equiv x_{i t}-h_{i t}$. Thus either harvest or escapement can be selected as the choice variable. In what follows, we will choose optimal escapement. Between periods, the fish stock grows. The growth function in each patch, $f\left(e_{i t}\right)$ is continuous, increasing, and concave. ${ }^{2}$ Because of ocean currents, fish migrate from patch A to patch $B$. Assume that all fish in patch $B$ at the end of period $t$ start period $t+1$ in patch $B$, and that some fraction $\theta$ of fish in patch $A$ at the end of period $t$ migrate to patch $B$ at the start of period $t+1$. The equations of motion for stocks in the two patches are thus

$$
\begin{aligned}
& x_{A t+1}=(1-\theta) f\left(e_{A t}\right), \\
& x_{B t+1}=\theta f\left(e_{A t}\right)+f\left(e_{B t}\right) .
\end{aligned}
$$

As a benchmark, consider the case in which these patches are completely independent (i.e., $\theta=0$ ). In this case, we can apply standard economic intuition to derive optimal escapement in each patch independently: In each patch the optimal escapement, $e^{*}$, is characterized by the stock level at which the rate of growth of the fish stock (the biological rate of return) equals the financial rate of return:

$$
f^{\prime}\left(e^{*}\right)=1 / \delta \text {. }
$$

This result is the standard "golden rule" of growth as applied to resource economics. This result holds whenever there is positive harvest. If the fishery begins a period with depleted stock such that $x_{i t}<e^{*}$, then it is optimal to close the fishery that period because the biological return from leaving fish in the ocean is greater than the financial rate of return. Such closures, however, would only be temporary, allowing depleted stocks to replenish. In steady state, optimal harvest would be positive in each patch. Establishing a biological reserve that would result in permanent closure of a patch would only reduce profits.

\footnotetext{
${ }^{2}$ We assume that $f^{\prime}(0)>1 / \delta$. If not, it would be optimal to fish to extinction and simply invest returns in a financial asset [4].
} 


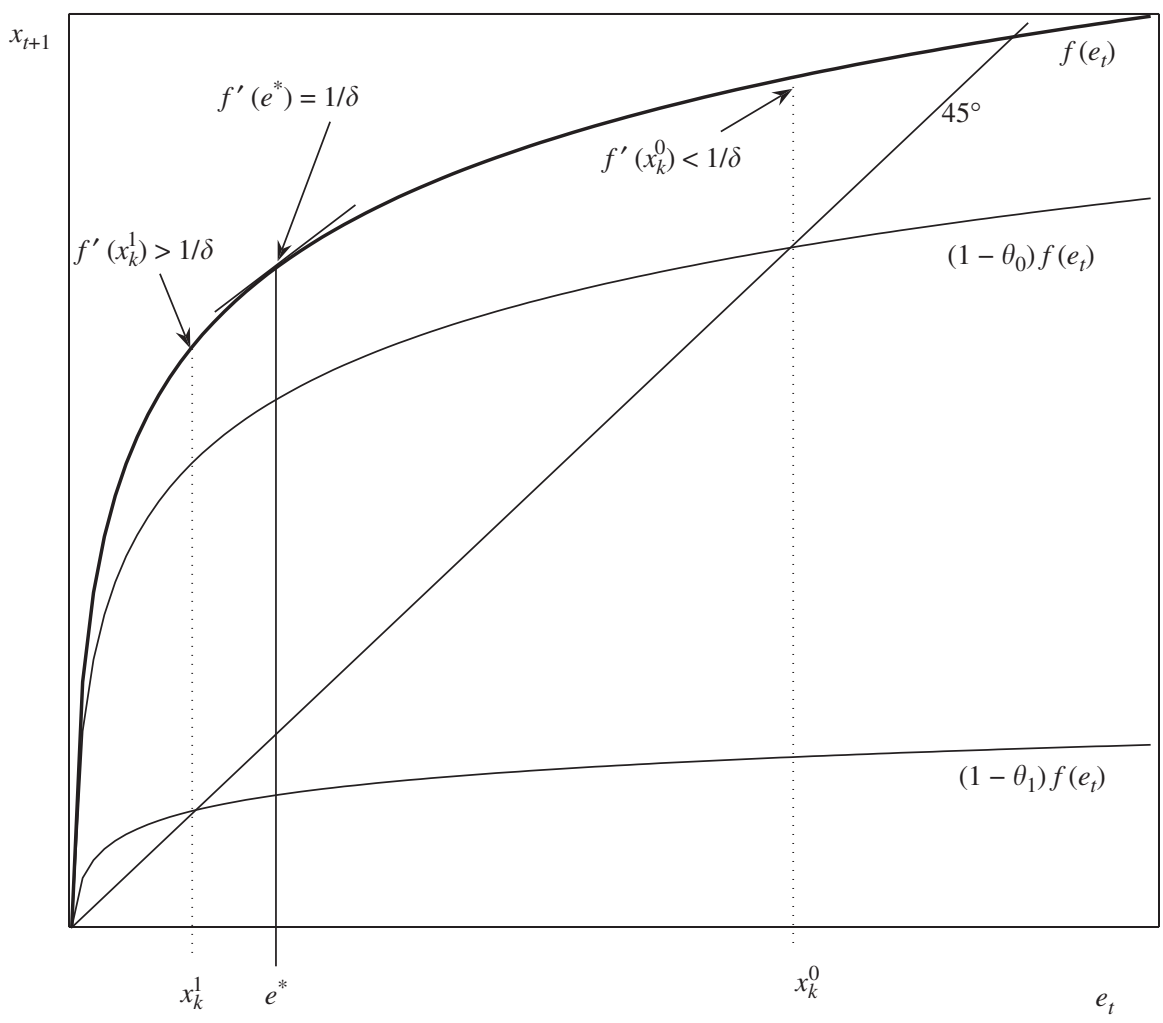

Fig. 1. Biological production in patch $A$ is given by $f(e)$. Because fish migrate from patch $A$ to patch $B$, only $(1-\theta) f(e)$ fish remain in patch $A$. With no harvest, the steady state stock of fish in patch $A$ is determined by the intersection of $(1-\theta) f(e)$ with the $45^{\circ}$ line. For high values of $\theta$, the no harvest steady state stock will lie to the left of $e^{*}$, as shown with high migration value $\theta_{1}$. Because $x_{k}^{1}<e^{*}$, the biological return in patch $A\left(f^{\prime}\left(x_{k}^{1}\right)\right)$ exceeds the financial return $(1 / \delta)$ and it is optimal to close patch $A$ to harvest.

When spatial connections exist $(\theta>0)$ establishing a permanent biological reserve may indeed be economically optimal, even in this simple example. The optimal strategy in each patch is still to harvest to the point where the growth rate of the resource equals the financial rate of return (as described in Eq. (3)). However, because fish migrate from patch $A$ to patch $B$, the fish stock in patch $A$ may be small, even when there is no harvest in patch $A$. Let the steady state stock in patch $A$ in the absence of harvest be given by $x_{k}$, which is implicitly defined by: $x_{k}=(1-\theta) f\left(x_{k}\right)$. As $\theta$ increases, $x_{k}$ decreases. For sufficiently large $\theta, x_{k}<e^{*}$, and it will be optimal to permanently close patch $A$ to harvesting. This is illustrated in Fig. 1 for the case of high spillover, $\theta_{1}$, which implies a low steady state stock: $x_{k}^{1}<e^{*}$. In this case, patch $A$ is a biological source that should be protected. It is optimal to close the fishery in patch $A$ because the biological return from leaving fish in patch $A$ is greater than the financial rate of return. Some of the fish from patch $A$ then migrate to patch $B$ where harvest occurs. For a low spillover rate, $\theta_{0}, x_{k}^{0}>e^{*}$, and it is not optimal to establish a biological reserve. ${ }^{3}$

\section{The spatial harvest problem}

Here we generalize the above spatial harvesting model. Harvest can take place in $i=1,2, \ldots, I$ discrete nonoverlapping patches over $t=1,2, \ldots, \infty$ discrete time periods. Patches may be heterogeneous along economic and/or biological dimensions. The model includes stochasticity in several key biological relationships, which is an important feature of most renewable resources.

\footnotetext{
${ }^{3}$ Except in the trivial case in which harvesting a patch is simply unprofitable.
} 


\subsection{Spatial biology}

The stock in patch $i$ at the start of period $t, x_{i t}$, is assumed to be known at the start of period $t$, for $i=1,2, \ldots, I$ and $t=1,2, \ldots$. Initial stock in each patch, $x_{i 1}$, is given. Harvest in patch $i$ in period $t$ is $h_{i t}$ and escapement in patch $i$ at the end of period $t$ is $e_{i t}$, with $e_{i t} \equiv x_{i t}-h_{i t}$. Biological production in each patch yields the stock of young, $Y_{i t}$, which depends on a spatially distinct average growth function of escapement $f_{i}\left(e_{i t}\right)$, with $f_{i}^{\prime}\left(e_{i t}\right)>0, f_{i}^{\prime \prime}\left(e_{i t}\right)<0$, and $f_{i}^{\prime}(0)>1 / \delta$. Growth may also be influenced by stochastic processes such as nutrient availability, rainfall, upwelling, and temperature [3]. The number of young produced in patch $i$ at time $t$ is

$$
Y_{i t}=Z_{i t}^{f} f_{i}\left(e_{i t}\right) \text {, }
$$

where $Z_{i t}^{f}$ is a random variable whose distribution is known and is time independent with expected value equal to 1 and support bounded below by 0 and finite upper support. Eq. (4) is a stochastic growth function considered by Reed [36], Costello et al. [9], and others.

The young that are produced in each patch $i=1, \ldots, I$ then disperse across space. The pattern of dispersal may be stochastic (dependent on ocean currents, wind, etc.). Denote by $D_{j i}$ a scaled multinomial random variable indicating the percentage of young that originate in patch $j$ that settle in patch $i$ (so $\sum_{i} D_{j i}=1$ ). We require some local retention: $D_{i i}>0$. Keeping track of all possible source locations, total settlement to patch $i$ is

$$
S_{i t}=\sum_{j=1}^{I} Y_{j t} D_{j i} .
$$

Following settlement in a patch, we assume that individuals do not migrate out of that patch. Young are assumed to reach adulthood in one time period, at which time they become harvestable and can reproduce. The number of settlers in patch $i$ that survive the time period to adulthood is $Z_{i t}^{S} \sigma_{i}\left(S_{i t}\right)$, where $\sigma_{i}\left(S_{i t}\right)$ is the (possibly) density dependent average survival to adulthood in patch $i, \sigma_{i}^{\prime}(s)>0$, and $Z_{i t}^{S}$ is a random variable. ${ }^{4}$ Adult survival from one period to the next is given by $Z_{i t}^{\mu} \mu_{i}\left(e_{i t}\right)$, where $\mu_{i}\left(e_{i t}\right)$ is the (possibly) density dependent average survival as a function of the number of adults after harvest and $Z_{i t}^{\mu}$ is a random variable. We assume that the distribution of $Z_{i t}^{S}$ and $Z_{i t}^{\mu}$ are known, time independent, each with expected value equal to 1 and support bounded below by $0 .{ }^{5} \mathrm{We}$ also assume that the random variables $\left(Z_{i t}^{f}, Z_{i t}^{S}, Z_{i t}^{\mu}, D_{j i}\right)$ are independent of each other.

Pulling together the various parts of the biological model, we can summarize the equation of motion describing the stock of adults in patch $i$ in time period $t+1$ as a random variable given by

$$
\begin{aligned}
x_{i t+1} & =Z_{i t}^{\mu} \mu_{i}\left(e_{i t}\right)+Z_{i t}^{S} \sigma_{i}\left(S_{i t}\right) \\
& =Z_{i t}^{\mu} \mu_{i}\left(e_{i t}\right)+Z_{i t}^{S} \sigma_{i}\left(\sum_{j=1}^{I} Z_{j t}^{f} f_{j}\left(e_{j t}\right) D_{j i}\right) .
\end{aligned}
$$

The first term on the right-hand side of Eq. (6) is the stock of surviving adults from the previous period. The second term on the right-hand side is the stock of new adults, which depends on reproduction and dispersal from all patches. Therefore, the stock in patch $i$ in time period $t+1$ may depend on escapement in all patches, $e_{j t}, j=1, \ldots, I$, and on the random variables in all patches, $Z_{j t}^{f}$ and $D_{j i}, j=1, \ldots, I$, as well as patch specific random variables, $Z_{i t}^{\mu}$, and $Z_{i t}^{S}$. The timing of growth and harvest are summarized in Fig. 2.

\footnotetext{
${ }^{4}$ We make the simplifying assumption that all adults in a patch have equal reproductive capacity. A more realistic (though less tractable) treatment would allow for age structure in both survivorship and reproduction.

${ }^{5}$ A technical restriction is that the upper bound on the support of $Z_{i t}^{S}$ cannot exceed $S / \sigma(S)$ and that the upper bound on the support of $Z_{i t}^{\mu}$ cannot exceed $e / \sigma(e)$. This ensures that the survivorship rate (of larvae and adults, respectively) cannot exceed 1.
} 


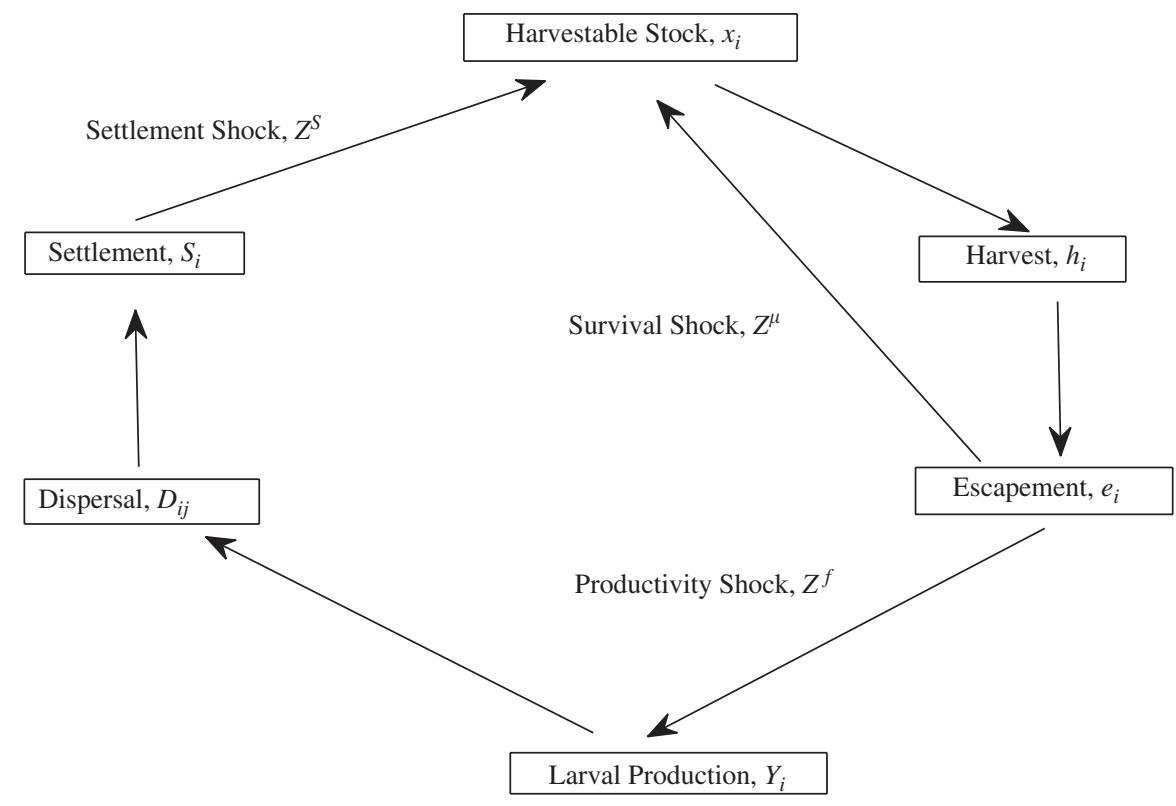

Fig. 2. Timing of growth, dispersal, and harvest in a stochastic spatially connected renewable resource model.

\subsection{Spatial economics}

We assume an elastic demand at price $p$ per unit harvest, and a marginal cost of harvest function, $c_{i}(s)$, which is a non-increasing function of the current stock, $c_{i}^{\prime}(s) \leqslant 0$. By indexing $c_{i}(\cdot)$ by $i$ we allow for the possibility that harvest costs may be location specific. For example marginal harvest costs in fishing may increase with depth or distance to port. The patch- $i$ period- $t$ payoff from harvest $h_{i t}$ starting with a population of $x_{i t}$ and ending with a population of $e_{i t}$ is: $p h_{i t}-\int_{e_{i t}}^{x_{i t}} c(s) \mathrm{d} s .{ }^{6}$ Henceforth we use the identity $h_{i t} \equiv x_{i t}-e_{i t}$ to rewrite the payoff function in terms of escapement: $p\left(x_{i t}-e_{i t}\right)-\int_{e_{i t}}^{x_{i t}} c(s) \mathrm{d} s$. Focusing on optimal escapement rather than optimal harvest significantly simplifies analysis of the model $[36,9]$.

The economic objective is to maximize the expected net present value of harvest, expressed in terms of escapement, from $I$-patches over an infinite horizon:

$$
\max _{\left\{e_{i t}\right\}} E \sum_{t=1}^{\infty} \delta^{t} \sum_{i=1}^{I}\left[p\left(x_{i t}-e_{i t}\right)-\int_{e_{i t}}^{x_{i t}} c(s) \mathrm{d} s\right],
$$

where the expectation operator, $E$, is over all future stocks. The maximization problem is subject to the equation of motion for stock in each patch $i=1,2, \ldots, I$ (Eq. (6)), and given initial stocks $x_{i 1}$, for all $i$. The objective is to identify a feedback control rule $\mathbf{e}_{t}^{*}\left(\mathbf{x}_{t}\right)$ that is an $I$-vector function of state-dependent controls that yields the optimal patch-specific escapement as a function of the vector of patch-specific stocks in any period $t$.

\section{Results}

In this section we derive an analytic solution to the stochastic spatial optimal harvesting problem in Eq. (7). We begin by deriving an interior solution and the conditions required for its existence. We then analyze the bioeconomically relevant and interesting corner solution case where it is optimal to close at least one patch to harvesting, either temporarily or permanently. A question central to this analysis is if, and under what biological or economic conditions, such closures emerge as part of the optimal solution.

\footnotetext{
${ }^{6}$ This payoff function rules out a capacity constraint on the fishing fleet size that would restrict large harvests in highly productive years.
} 
We represent the spatial harvesting problem under uncertainty as a stochastic dynamic programming equation with $\mathbf{x}_{t}$ as the period- $t$ state vector of stocks and $\mathbf{e}_{t}$ as the period- $t$ control vector, as follows:

$$
V_{t}\left(\mathbf{x}_{t}\right)=\max _{\mathbf{e}_{t}} \sum_{i=1}^{I}\left[p\left(x_{i t}-e_{i t}\right)-\int_{e_{i t}}^{x_{i t}} c(s) \mathrm{d} s\right]+\delta E_{t}\left\{V_{t+1}\left(\mathbf{x}_{t+1}\right)\right\} .
$$

Eq. (8) is subject to state transitions given by Eq. (6) and initial stocks $\mathbf{x}_{1}$. From the perspective of period-t, period $t+1$ stocks are random variables. Thus the period $t$ problem requires taking expectations, $E_{t}$, over the random variable $V_{t+1}\left(\mathbf{x}_{t+1}\right)$. Solving for the optimal solution requires setting the marginal value of harvest in each patch equal to the discounted expected marginal value of additional escapement from the patch, where the marginal value of additional escapement is determined by its contribution to future harvests in connected patches.

In general, stochastic dynamic programming equations such as Eq. (8) are difficult problems to solve analytically. However, we can make progress in the analysis by taking advantage of the special structure of the problem. Define $\underline{x}_{i}$ as the stock level to which a myopic harvester would extract the resource: $\underline{x}_{i}=\max \left(0, \hat{x}_{i}\right)$, where $\hat{x}_{i}$ is the level of stock at which marginal profit is zero, defined by $p=c\left(\hat{x}_{i}\right)$. Starting with a stock of $x$, the patch-i period-t profit from harvesting down to $\underline{x}_{i}$ is given as follows:

$$
Q_{i}(x) \equiv p\left(x-\underline{x}_{i}\right)-\int_{\underline{x}_{i}}^{x} c_{i}(s) \mathrm{d} s .
$$

Using this function, we can re-write the dynamic programming Eq. (8) as follows:

$$
V_{t}\left(\mathbf{x}_{t}\right)=\max _{\mathbf{e}_{t}} \sum_{i=1}^{I}\left[Q_{i}\left(x_{i t}\right)-Q_{i}\left(e_{i t}\right)\right]+\delta E_{t}\left\{V_{t+1}\left(\mathbf{x}_{t+1}\right)\right\},
$$

which is subject to biological state transitions given in Eq. (6) and initial stocks $\mathbf{x}_{1}$. We represent optimal solutions to this problem by $\mathbf{e}_{t}^{*}\left(\mathbf{x}_{t}\right)$. We assume concavity of returns in $\mathbf{e}_{t}$ so that there is a unique solution $\mathbf{e}_{t}^{*}\left(\mathbf{x}_{t}\right)$. Under the assumptions of our model, we can guarantee concavity when $f_{i}^{\prime \prime}(\cdot)$ is large in absolute value (highly concave growth function) relative to $c_{i}^{\prime \prime}(\cdot)$.

\subsection{An interior solution to the stochastic spatial harvesting problem}

Making use of the form of the stochastic dynamic program in Eq. (10), we can show that the optimal escapement in this harvesting problem is independent of the state vector, a condition for which we adopt the following definition:

Definition 1. A discrete-time stochastic dynamic optimization problem has "state independent control" if the optimal control in any period $t$ is independent of the state vector in that period. ${ }^{7}$

State independent control problems have a special structure that allows one to break stochastic dynamic optimization problems, normally quite difficult to solve, into a series of one-period optimization problems, which are relatively easy to solve. In state independent control problems, the optimum choice vector $\left(\mathbf{e}_{t}\right)$ is determined solely by factors independent of the state vector $\left(\mathbf{x}_{t}\right)$. In our case, state independent control means that the optimal choice of escapement can depend on the discount factor, price, marginal cost of harvesting at the level of escapement, expected biological growth, dispersal, and survival of stock to the next period, but will not depend on level of stock at the beginning of the period. When optimal escapement in period $t$ is independent of initial stock in period $t$, optimal escapement will be independent of all past choices of escapement because these choices affect the period $t$ choice only through the initial level of stock. Similarly, optimal escapement in period $t$ will not affect any future escapement decisions because those choices will also be independent from all past choices. State independent control is a strong property and does not hold in

\footnotetext{
${ }^{7}$ The notion of state independent control is similar to "state separability," a concept applied in non-cooperative differential games [11]. State separability requires state independent control and an additional condition relevant for continuous time models.
} 
general. In the following lemma, we show that our problem has state independent control under an interior solution.

Lemma 1. Provided that an interior solution exists, the period t dynamic program given in Eq. (10) has state independent control.

Proof. The dynamic programming equation is

$$
V_{t}\left(\mathbf{x}_{t}\right)=\max _{\mathbf{e}_{t}} \underbrace{\sum_{i=1}^{I}\left[Q_{i}\left(x_{i t}\right)-Q_{i}\left(e_{i t}\right)\right]}_{\text {Current Payoff }}+\underbrace{\delta E_{t}\left\{V_{t+1}\left(\mathbf{x}_{t+1}\right)\right\}}_{\text {Future Payoff }} .
$$

The necessary condition for an interior solution is

$$
-Q_{i}^{\prime}\left(e_{i t}\right)+\delta E_{t}\left\{\sum_{j=1}^{I} \frac{\partial V_{t+1}\left(x_{t+1}\right)}{\partial x_{j t+1}} \frac{\partial x_{j t+1}}{\partial e_{i t}}\right\}=0 \quad \forall i
$$

The necessary condition is also sufficient given the assumption of concavity of returns in the vector of controls (escapement). The first term, which reflects the marginal contribution of escapement to current period payoff, is independent of $\mathbf{x}_{t}$ by inspection. The derivative of the value function in period $t+1$ depends on the period $t+1$ state, but is independent of the period $t$ state. Noting that for an interior solution $e_{i t}<x_{i t}$ and using Eq. (6) observe that $x_{i t+1}$ is a function of $e_{i t}$ but not of $x_{i t}$. Therefore, the terms in the bracket are independent of $\mathbf{x}_{t}$, and the period $t$ problem has state independent control.

An important economic insight that follows from the state independent control property is captured in the following proposition:

Proposition 1. If an interior solution to the dynamic programming equation exists, the optimal feedback control rule will be both time and state independent and will, in general, vary across space.

Proof. The necessary condition for an interior optimal solution to the dynamic programming equation (Eq. (10)) for patch $i$ at time $t$ is given by Eq. (12). Note that $e_{i t}^{*}$ is independent of $x_{i t}$ by Lemma 1 . Therefore, a change in stock in the next period affects the value function in $t+1$ only through terms $Q_{j}\left(x_{j t+1}\right)$, for $j=1, \ldots, I$. Using this fact along with the state transition equations (Eq. (6)), we can rewrite the necessary condition for patch $i$ at time $t$ as follows:

$$
-Q_{i}^{\prime}\left(e_{i t}^{*}\right)+\delta E_{t}\left\{Q_{i}^{\prime}\left(x_{i t+1}\right) Z_{i t}^{\mu} \mu_{i}^{\prime}\left(e_{i t}^{*}\right)+\sum_{j=1}^{I} Q_{j}^{\prime}\left(x_{j t+1}\right) Z_{j t}^{S} \sigma_{j}^{\prime}(\cdot) Z_{i t}^{f} f_{i}^{\prime}\left(e_{i t}^{*}\right) D_{i j}\right\}=0 .
$$

Since the distribution of shocks is independent of time, as is biological growth, dispersal, survival and economic returns, the optimal choice, $e_{i t}^{*}$, is independent of time. However, since biological growth, dispersal, and economic returns can vary across patches, the optimal choice will, in general, vary across space.

The optimal solution to the dynamic spatial harvesting problem under uncertainty is a patch-specific constant escapement level. This result is a generalization to the spatial context of a result derived by Reed [36]. For a given patch, the optimal escapement level remains fixed over time because expectations are constant across periods. Escapement is an investment whose cost is the lost value of current harvest and whose return is the expected discounted value of increased future harvest. Optimal escapement in patch $i\left(e_{i t}^{*}\right)$ is determined by the level of ending stock at which the marginal profit of current harvest, $-Q_{i}^{\prime}\left(e_{i t}^{*}\right)=p-c_{i}\left(e_{i t}^{*}\right)$, is equal to the discounted expected marginal profit of next period harvest, which is the term in the brackets in Eq. (13). Allowing higher escapement contributes to next period profits because there will be a larger expected harvestable stock in patch $i, E_{t}\left\{Z_{i t}^{\mu} \mu_{i}^{\prime}\left(e_{i t}^{*}\right)\right\}$, and a larger expected number of new recruits in many patches from biological growth, dispersal and survival, $E_{t}\left\{\sum_{j=1}^{I} Z_{j t}^{S} \sigma_{j}^{\prime}(\cdot) Z_{i t}^{f} f_{i}^{\prime}\left(e_{i t}^{*}\right) D_{i j}\right\}$. The expected marginal value of harvest from increased initial stock in patch $j$ in the next period is given by $Q_{j}^{\prime}\left(x_{i t+1}\right)$. Environmental fluctuations that affect initial stock size in a patch will affect harvest. When conditions are good and initial stocks are high there will be large harvests, and when conditions are poor and initial stocks are low there will be small harvests. In 
both good and poor conditions, however, escapement remains constant because the tradeoff between current cost and expected future gain remains constant.

Though each patch retains constant escapement, optimal escapement levels can vary across space for three reasons. First, spatial heterogeneity in the economic environment (captured here by different harvest costs) can drive spatial differentiation of harvest. Second, spatial heterogeneity in the biological environment (captured by differences in biological productivity across patches) will influence harvesting. Finally, and perhaps most importantly, patterns of dispersal, which connect the biological functions of different patches, can affect harvest. These spatial connections are what distinguish this problem from similar analyses in aspatial environments and can play an important role in determining the optimal harvest strategy. However, there is a set of special conditions under which spatial connectivity plays no role in the interior solution.

Condition 1. The marginal harvest cost function is constant and identical across patches $\left(\right.$ so $\left.c_{i}(s)=c\right)$.

Condition 2. The survival function $\sigma_{j}(x)$ is linear and identical across patches $\left(\right.$ so $\left.\sigma_{j}(x)=\sigma x\right)$.

Proposition 2. Under Conditions 1 and 2, and provided that an interior solution to the dynamic programming equation exists, the optimal feedback control rule satisfies the golden rule of growth in each patch in each time period and is independent of dispersal.

Proof. Under Condition 1, $Q_{i}(x)=(p-c)\left(x-\underline{x}_{i}\right)$. Under Condition 2, $\sigma_{j}^{\prime}(\cdot)=\sigma$. Using these facts, the necessary condition for an interior solution to the optimal feedback rule for patch $i$ at time $t$ is

$$
-(p-c)+\delta E_{t}\left\{(p-c) Z_{i t}^{\mu} \mu_{i}^{\prime}\left(e_{i t}^{*}\right)+\sum_{j=1}^{I}(p-c) Z_{j t}^{S} \sigma Z_{i t}^{f} f_{i}^{\prime}\left(e_{i t}^{*}\right) D_{i j}\right\}=0 .
$$

Simplifying this expression we obtain: $1=\delta\left\{\mu_{i}^{\prime}\left(e_{i t}^{*}\right)+\sum_{j=1}^{I} \sigma f_{i}^{\prime}\left(e_{i t}^{*}\right) D_{i j}\right\}$. Using the fact that $\sum_{j=1}^{I} D_{i j}=1$, this expression can be further simplified to

$$
1 / \delta=\mu_{i}^{\prime}\left(e_{i t}^{*}\right)+\sigma f_{i}^{\prime}\left(e_{i t}^{*}\right) \text {. }
$$

Optimal escapement in a patch, as characterized by Eq. (15), is independent of dispersal. The left-hand side of Eq. (15) is equal to the financial rate of return $(1 / \delta=1+r$, where $r$ is the interest rate). The right-hand side of Eq. (15) is the expected biological growth of the stock. Eq. (15) shows that the golden rule of growth holds in each patch in each period: the expected biological growth of the stock equals the financial rate of return.

In an interior solution with identical linear costs and constant survival rates across sites, a recruit will contribute the same value to future production no matter where it ends up. Survival rates are constant, not density dependent, and identical so that a recruit is just as likely to survive to be harvested in any patch. Further, the marginal value of harvest in all patches in all periods is the same, $p-c$. Under Conditions 1 and 2 , what matters is the marginal productivity of a site, $\mu_{i}^{\prime}\left(e_{i t}^{*}\right)+\sigma f_{i}^{\prime}\left(e_{i t}^{*}\right)$, but not where the recruits from a site disperse.

Spatial connections are irrelevant only in the special case where Conditions 1 and 2 apply. In general, with non-linear density dependent survival, differences in survival rates across patches, non-linear harvest costs, or differences in harvest costs across patches, dispersal will play a role in optimal escapements.

\subsection{Corner solutions: a case for biological reserves?}

Over the past several decades there has been a major expansion of protected areas ("reserves") in which extractive economic activities, such as timber harvesting, hunting, or fishing, are banned or restricted. Currently about $10 \%$ of the earth's land area (almost twice the size of Europe or Australia) and 5\% of the territorial oceans (about 20 times the area of the Great Lakes) are in reserves. ${ }^{8}$

One justification for expanding reserves is to achieve biological objectives; reserves are a means to conserve biodiversity. However, a stronger claim is often made that reserves increase the value of extractive economic

\footnotetext{
${ }^{8}$ Authors' calculations based on data in World Database on Protected Areas [51]. Total land area is $1.48 \mathrm{E} 10$ ha and total terrestrial reserves constitute $1.47 \mathrm{E} 9 \mathrm{ha}$. Total territorial and EEZ ocean area is $1.07 \mathrm{E} 10$ ha and total marine protected area is $4.8 \mathrm{E} 8 \mathrm{ha}$.
} 
activity. That this is so does not immediately accord with economic intuition [8]. Provided that the initial stock size in every patch in every period is sufficiently large, an interior solution (in which there is positive harvest in every patch in every period) is optimal. But with stochasticity and spatially connected patches there is no guarantee that initial stock size in every patch in every period will be sufficiently large. In this section we focus on corner solution cases where it is optimal to close a patch, either temporarily or permanently, to harvest. We begin with the following result.

Proposition 3. Patch $i$ should be closed to harvesting in period $t$ if and only if $x_{i t}<\bar{e}_{i t}$, where $\bar{e}_{i t}$ satisfies the following implicit equation:

$$
-Q_{i}^{\prime}\left(\bar{e}_{i t}\right)+\delta E_{t}\left\{\sum_{j=1}^{I} \frac{\partial V_{t+1}\left(x_{t+1}\right)}{\partial x_{j t+1}} \frac{\partial x_{j t+1}}{\partial e_{i t}}\right\}=0 .
$$

Proof. Because $-Q_{i}^{\prime \prime}(e)<0$, and

$$
\frac{\partial}{\partial e_{i t}}\left\{E_{t}\left(\sum_{j=1}^{I} \frac{\partial V_{t+1}\left(x_{t+1}\right)}{\partial x_{j t+1}} \frac{\partial x_{j t+1}}{\partial e_{i t}}\right)\right\}<0
$$

we have

$$
-Q_{i}^{\prime}\left(e_{i t}\right)+\delta E_{t}\left\{\sum_{j=1}^{I} \frac{\partial V_{t+1}\left(x_{t+1}\right)}{\partial x_{j t+1}} \frac{\partial x_{j t+1}}{\partial e_{i t}}\right\}>0
$$

for $e_{i t}<\bar{e}_{i t}$. In this case, it is optimal to increase escapement. However, we know that $e_{i t} \leqslant x_{i t}$, so if $x_{i t}<\bar{e}_{i t}$, the maximum $e_{i t}$ that can be attained is $e_{i t}=x_{i t}$, which occurs with zero harvest. Therefore, for $x_{i t}<\bar{e}_{i t}$ it is optimal to close patch $i$ to harvesting in period $t$. For $e_{i t}>\bar{e}_{i t},-Q_{i}^{\prime}\left(e_{i t}\right)+\delta E_{t}\left\{\sum_{j=1}^{I} \frac{\partial V_{t+1}\left(x_{t+1}\right)}{\partial x_{j t+1}} \frac{\partial x_{j t+1}}{\partial e_{i t}}\right\}<0$ and it is optimal to lower escapement (increase harvest). When $x_{i t} \geqslant \bar{e}_{i t}$, it is optimal to have positive harvest and have escapement of $e_{i t}=\bar{e}_{i t}$.

Proposition 3 provides a necessary and sufficient condition for a harvest closure to be economically optimal. If the initial stock in patch $i$ in period $t, x_{i t}$, falls below the patch specific escapement target, $\bar{e}_{i t}$, then the patch should be closed in that period because the expected biological returns from escapement exceed the returns from current harvest. It follows that if $x_{i t}<\bar{e}_{i t}$ for all $t$ then patch $i$ should be permanently closed to harvest. In that case, patch $i$ would be a permanent biological reserve. The example in Section 2 with large value of $\theta$ illustrates this possibility. Conditions that lead to low initial stock levels in a patch include low dispersal of recruits to the patch, low survival of recruits and low survival of adults. Having low survival of adults will also tend to result in a low optimal escapement level (if adults are unlikely to survive it is better to harvest them now), and may thus preclude establishing a permanent biological reserve. However, having permanently low dispersal into a patch or low survival of recruits in a patch will tend to favor a permanent biological reserve. There is value to maintaining the adult stock in a patch with low recruiting ability. The relatively rare adults in such a patch are most profitably suited to production (and subsequent harvest of recruits in connected patches) rather than harvest.

High harvest costs in a patch can also lead to reserves. When marginal harvest costs at all possible stock levels exceed price it is never optimal to harvest from the patch. Of course, in this case official designation as a biological reserve is relatively meaningless as no profit maximizing harvester would attempt to harvest from the patch. Even when harvest costs do not exceed price, it may be optimal to close patches with high harvest costs so that growth disperses and settles in patches with lower harvest costs.

With stochastic shocks to recruitment or the adult population, it is possible that $x_{i t}<\bar{e}_{i t}$ in some periods but not permanently, in which case it is optimal to have a temporary harvest ban, i.e., a temporary reserve, in a particular set of patches to allow stock recovery, but not institute a permanent biological reserve. We return to this point in Section 4.3. A result that follows immediately from this discussion is that patches in which stocks have been depleted by past harvesting (such that $x_{i t}<\bar{e}_{i t}$ ) should be closed to harvesting, at least temporarily, until stocks have recovered to a point where this inequality no longer holds. 
Even knowing which patches to close, the fishery owner is still faced with the task of determining optimal harvest outside the closed area. This question is of central importance to policy surrounding protected areas and their design, yet it has received only scant attention in the literature. When analyzing the consequences of harvest closures two different approaches have been taken. Biologists typically assume maximal harvest outside the reserve [22]. Of course in a world with stock-dependent harvest costs (such as assumed in this model) it would never be economically rational to harvest to extirpation in a patch (provided $c(0)>p$ ). Another approach is to assume some form of open access outside the reserve (e.g. Sanchirico and Wilen [40]). In either case, reserves may be better than no reserves because their implementation partially addresses the failures associated with over-harvesting.

Our interest here is to characterize how implementation of a reserve affects optimal harvest outside the reserve. Explicitly characterizing the optimal pattern of harvests with $N$ patches through time is complex because there are many potential patterns for which patches are open and which are closed to harvest though time, and as we show below, the optimal harvest in a patch can depend on which other patches are open and closed. To keep things simple and obtain sharp results, we focus on a comparison where potentially one patch will be closed for one period and all other patches are open for all periods. When all patches are at an interior solution, optimal escapement for patch $i$ at time $t, e_{i t}^{*}$, is characterized by Eq. (13). Define $x_{j t+1}^{*}$ to be the stock in patch $j$ in period $t+1$ when all patches $i=1,2, \ldots, I$, in period $t$ have escapement of $e_{i t}^{*}: x_{j t+1}^{*}=$ $Z_{j t}^{\mu} \mu_{j}^{\prime}\left(e_{j t}^{*}\right)+Z_{j t}^{S} \sigma_{j}\left(\sum Z_{i t}^{f} f_{i}^{\prime}\left(e_{i t}^{*}\right) D_{i j}\right)$. For suitable combinations of the patch specific growth functions $\left(f_{i}(\cdot)\right)$, survival functions $\left(\mu_{i}(\cdot)\right.$ and $\left.\sigma_{i}(\cdot)\right)$, and distributions of random variables $\left(Z_{i t}^{\mu}, Z_{i t}^{S}, Z_{i t}^{f}, D_{i j}\right)$, for all $i, j$, $t$, we can have $x_{i t}^{*} \geqslant e_{i t}^{*}$ for all $i$ and all $t$. For example in the two patch model shown in Fig. 1, assume that the value $\theta_{0}$ occurs for all $t$. We denote this case as

Case 1: Interior solution. $x_{i t}^{*} \geqslant e_{i t}^{*}$ for all $i$ and all $t$.

Now suppose that we take the exact same growth and survival functions and distributions of random variables, but impose a deleterious shock to stock in patch $k$ in period $\tau$. For example, suppose that $Z_{i \tau}^{\mu}$ and $Z_{i \tau}^{S}$ are close to zero so that $x_{i \tau}<\bar{e}_{i \tau}$, where $\bar{e}_{i \tau}$ is defined by Eq. (16). Alternatively in the two patch model shown in Fig. 1 with value $\theta_{0}$ for all $t \neq \tau-1$ and value $\theta_{1}$ for $t=\tau-1$. When some patch may not be at an interior solution, optimal escapement is characterized by Eq. (16). Define $\bar{x}_{j t+1}$ to be the stock in patch $j$ in period $t+1$ when all patches $i=1,2, \ldots, I$ in period $t$ have escapement of $\bar{e}_{i t}$. This case is denoted as

Case 2: Patch $k$ Corner solution. $\bar{x}_{i t} \geqslant \bar{e}_{i t}$ for all $i$ and all $t$ except that $\bar{x}_{k \tau}<\bar{e}_{k \tau}$ with non-zero probability.

We have the following results:

Proposition 4. The optimal escapement in patch $i$ at time $\tau-1$ is higher in Case 2 than in Case 1.

Proof. In Case 1 when patch $k$ is in an interior solution at time $\tau$, optimal escapement from patch $i$ in period $\tau-1, e_{i \tau-1}^{\{1\}}$, satisfies

$$
-Q^{\prime}\left(e_{i \tau-1}^{\{1\}}\right)+\delta E_{t}\left[Q^{\prime}\left(x_{i \tau}\right) Z_{i \tau-1}^{\mu} \mu_{i}^{\prime}\left(e_{i \tau-1}^{\{1\}}\right)+\sum_{j=1}^{I} Q_{j}^{\prime}\left(x_{j \tau}\right) Z_{j \tau-1}^{S} \sigma_{j}^{\prime}(\cdot) Z_{i \tau-1}^{f} f_{i}^{\prime}\left(e_{i \tau-1}^{\{1\}}\right) D_{i j}\right]=0 .
$$

In Case 2, when patch $k$ is in a corner solution at time $\tau$, the optimal escapement from patch $i$ in period $\tau-1$ $e_{i \tau-1}^{\{2\}}$, satisfies

$$
-Q^{\prime}\left(e_{i \tau-1}^{\{2\}}\right)+\delta E_{\tau-1}\left[\begin{array}{l}
Q^{\prime}\left(x_{i \tau}\right) Z_{i \tau-1}^{\mu} \mu_{i}^{\prime}\left(e_{i \tau-1}^{\{2\}}\right)+\sum Q_{j}^{\prime}\left(x_{j \tau}\right) Z_{j \tau-1}^{S} \sigma_{j}^{\prime}(\cdot) Z_{i \tau-1}^{f} f_{i}^{\prime}\left(e_{i \tau-1}^{\{2\}}\right) D_{i j} \\
+\delta E_{\tau}\left[\sum Q_{j}^{\prime}\left(x_{j \tau+1}\right) Z_{j \tau}^{S} \sigma_{j}^{\prime}(\cdot) Z_{k \tau}^{f} f_{k}^{\prime}\left(x_{k \tau}\right) D_{k j} Z_{k \tau-1}^{S} \sigma_{k}^{\prime}(\cdot) Z_{i \tau-1}^{f} f_{i}^{\prime}\left(e_{i \tau-1}^{\{2\}}\right) D_{i k}\right]
\end{array}\right]=0 .
$$

When patch $k$ is in a corner solution in period $\tau$,

$$
Q^{\prime}\left(x_{k \tau}\right)<\delta E_{\tau}\left[\sum Q_{j}^{\prime}\left(x_{j \tau+1}\right) Z_{j \tau}^{S} \sigma_{j}^{\prime}(\cdot) Z_{k \tau}^{f} f_{k}^{\prime}\left(x_{k \tau}\right) D_{k j}\right] .
$$

Substituting the inequality in Eq. (20) into Eq. (19) we find

$$
-Q^{\prime}\left(e_{i \tau-1}^{\{2\}}\right)+\delta E_{\tau-1}\left[Q^{\prime}\left(x_{i \tau}\right) Z_{i \tau-1}^{\mu} \mu_{i}^{\prime}\left(e_{i \tau-1}^{\{2\}}\right)+\sum Q_{j}^{\prime}\left(x_{j \tau}\right) Z_{j \tau-1}^{S} \sigma_{j}^{\prime}(\cdot) Z_{i \tau-1}^{f} f_{i}^{\prime}\left(e_{i \tau-1}^{\{2\}}\right) D_{i j}\right]<0 .
$$


Because the returns function is assumed to be concave in escapement (see text following Eq. (10)), so that the marginal returns function is declining in escapement, it follows from Eqs. (21) and (18) that $e_{i \tau-1}^{\{2\}}>e_{i \tau-1}^{\{1\}}$.

Proposition 5. When it is optimal to open all patches to harvest in all periods (Case 1) and assuming that $\operatorname{Pr}\left(D_{i k}=0\right)<1$, then optimal escapement in patch $i$ at time $\tau$ will be lower when patch $k$ is (sub-optimally) closed to harvest in period $\tau$ than when patch $k$ is open at time $\tau$.

Proof. When harvest is allowed in patch $k$ at time $\tau$, optimal escapement from patch $i$ in period $\tau-1$ is defined in Eq. (18). When harvest is closed in patch $k$ in period $\tau$, optimal escapement from patch $i$ in period $\tau-1$ is defined in Eq. (19). Because it is optimal for patch $k$ to be open in period $\tau$ but it is closed to harvest, we have

$$
Q^{\prime}\left(x_{k \tau}\right)>\delta E_{\tau}\left[\sum Q_{j}^{\prime}\left(x_{j \tau+1}\right) Z_{j \tau}^{S} \sigma_{j}^{\prime}(\cdot) Z_{k \tau}^{f} f_{k}^{\prime}\left(x_{k \tau}\right) D_{k j}\right] .
$$

Substituting the inequality in Eq. (22) into Eq. (19) we find

$$
-Q^{\prime}\left(e_{i \tau-1}^{\{2\}}\right)+\delta E_{\tau-1}\left[Q^{\prime}\left(x_{i \tau}\right) Z_{i \tau-1}^{\mu} \mu_{i}^{\prime}\left(e_{i \tau-1}^{\{2\}}\right)+\sum Q_{j}^{\prime}\left(x_{j \tau}\right) Z_{j \tau-1}^{S} \sigma_{j}^{\prime}(\cdot) Z_{i \tau-1}^{f} f_{i}^{\prime}\left(e_{i \tau-1}^{\{2\}}\right) D_{i j}\right]>0
$$

Because the returns function is assumed to be concave in escapement, so that the marginal returns function is declining in escapement, it follows from Eqs. (23) and (18) that $e_{i \tau-1}^{\{2\}}<e_{i \tau-1}^{\{1\}}$.

As a consequence of Proposition 3, it is optimal to close a patch to harvest when the marginal productivity in the closed patch exceeds the financial rate of return. When other patches contribute (through dispersal) to settlement in the closed patch, this contribution has high returns. Therefore, it is optimal to allow higher escapement (lower harvest) outside the optimally designed reserve (Proposition 4). On the other hand, when a patch is closed arbitrarily (i.e., it is closed when it is not optimal to do so), the patch will have low productivity. Other patches that contribute to settlement in this patch through dispersal will have lower returns. Therefore, it is optimal to allow lower escapement (higher harvest) outside the (suboptimally designed) reserve (Proposition 5).

\subsection{Effects of stochasticity}

We have characterized optimal escapement for an interior solution (Section 4.1) and a corner solution (Section 4.2). In this section we analyze the consequences of stochasticity on: (1) the optimality of biological reserves, (2) the expected value of harvesting the resource, and (3) the optimal escapement levels outside reserves. We analyze the effects of increased variability using a mean-preserving spread of a distribution of a random variable (some collection of $Z_{i}^{f}, Z_{i}^{\mu}$, and $Z_{i}^{S}$ ). ${ }^{9}$ We denote by $\xi$ the distribution of one of these random variables. In what follows, it will be helpful to define a special condition under which optimal escapement is strictly positive.

Condition 3. It is unprofitable to harvest any patch to extinction: $\hat{x}_{i}=\underline{x}_{i}>0$.

Under Condition 3, the stock effect gets sufficiently large so that marginal cost of harvest rises above price at low stock levels making local extinction unprofitable. This provides a sufficient condition for the following proposition:

Proposition 6. Suppose an interior solution is optimal for all patches in all time periods and that Condition 3 holds. A sufficiently large mean preserving spread over the distributions governing some combination of $Z_{i}^{f}, Z_{i}^{\mu}$, and $Z_{i}^{S}$ will induce optimal temporary closures in patch $i$.

Proof. Under Condition $3, \bar{e}_{i t}(\xi) \geqslant \hat{x}_{i}>0$ for all $i$ and $t$ for all possible distributions of the random variables. By Proposition 3, it is optimal to close patch $i$ to harvesting in period $t$ if and only if $x_{i t}<\bar{e}_{i t}(\xi)$. From Eq. (6) increasing the spread of the distribution of any $Z_{i}^{f}, Z_{i}^{\mu}$, or $Z_{i}^{S}$ will make the minimum possible realization of $x_{i t}$ arbitrarily close to zero so that $x_{i t}<\bar{e}_{i t}(\xi)$ for some $i, t$, and $\xi$.

\footnotetext{
${ }^{9}$ When referring to a distribution of a random variable, we omit the subscript $t$ since the distributions themselves are independent of time.
} 
Proposition 6 shows that a suitably large increase in variability makes it optimal to close a patch to harvest, at least temporarily. Increased variability leads to a lower support on the distribution. With sufficiently large spread, the lower support on the distribution will fall below the optimal escapement level so that a deleterious shock will cause initial stock in a period to fall below the optimal escapement, leading to optimal closure of the patch. $^{10}$

The same mechanism underlies a corollary result: increased variability tends to reduce the likelihood of an optimal permanent reserve. This occurs because a combination of good shocks to growth, dispersal and survival will make it likely that $x_{i t}>\bar{e}_{i t}(\xi)$ for some $t$, and it will be optimal to open the patch to harvesting, at least on a temporary basis. In other words, without imposing an upper limit on the support of the random variables in this model, we cannot guarantee that permanent reserves will be optimal. However, if the adult and recruit survival functions are suitably small and the upper bound on the support of random variables is finite, then $x_{i t}<\bar{e}_{i t}(\xi)$ for all $t$ and permanent closure will be optimal.

In summary, increasing the spread of random variables makes permanent reserves and permanent open patches less likely and increases the probability of temporary closures in an optimal solution. With high variability it is likely that there will be realizations of the random variable that place initial stock in a period either above or below the critical threshold level characterized by Eq. (16) so that decisions about whether to allow harvesting can go either way.

Changes in environmental variability can also affect optimal escapement levels outside of reserves, which we discuss in the next proposition.

Proposition 7. Adopting Conditions 1 and 2 and the patch-k corner solution case (Case 2), a mean preserving spread on any random variable that directly affects $x_{k \tau}$ causes $e_{i \tau-1}$ to increase (decrease) if $f_{k}^{\prime \prime \prime}\left(x_{k}\right)$ is $>0(<0)$, where $i$ is a patch for which $D_{i k}>0$.

Proof. Define the expected present value of payoff from harvest starting from period $\tau-1$ as $E_{\tau-1} U(e, x)=\sum_{t=\tau-1}^{\infty} \delta^{t-(\tau-1)} \sum_{i=1}^{I}\left[Q_{i}\left(x_{i t}\right)-Q_{i}\left(e_{i t}\right)\right]$. Let the distribution of $x_{k \tau}$ be a function of $\xi$, where an increase in $\xi$ denotes a mean preserving spread. Let $e_{i \tau-1}^{*}(\xi)$ denote the optimal choice of $e_{i \tau-1}$ when the distribution of $x_{k \tau}$ has spread $\xi$. We wish to evaluate the sign of $\left(d e_{i \tau-1}^{*}(\xi)\right) / d \xi$. Laffont [29] proves the following (Theorem 2):

$$
\frac{d e_{i \tau-1}^{*}(\xi)}{d \xi} \begin{cases}>0 & \text { if } U_{e x x}>0 \\ <0 & \text { if } U_{e x x}<0\end{cases}
$$

where $U_{e x x}$ is the third derivative of the utility function with respect to $e$ and $x$ (twice). The first derivative, $U_{e_{i \tau-1}}$ is given by the left-hand side of Eq. (19). Conditions 1 and 2 simplify it to

$$
U_{e_{i \tau-1}}=-1+\delta E_{\tau-1}\left[\begin{array}{l}
Z_{i \tau-1}^{\mu} \mu_{i}^{\prime}\left(e_{i \tau-1}\right)+\sum Z_{j \tau-1}^{S} \sigma Z_{i \tau-1}^{f} f_{i}^{\prime}\left(e_{i \tau-1}\right) D_{i j} \\
+\delta E_{\tau}\left[\sum\left(Z_{j \tau}^{S} \sigma Z_{k \tau}^{f} f_{k}^{\prime}\left(x_{k \tau}\right) D_{k j} Z_{k \tau-1}^{S} \sigma Z_{i \tau-1}^{f} f_{i}^{\prime}\left(e_{i \tau-1}\right) D_{i k}\right]\right.
\end{array}\right]
$$

Laffont's theorem requires us to take the second derivative of this expression with respect to $x_{k \tau}$, which is equal to

$$
U_{\text {exx }}=\delta E_{\tau-1}\left[\delta E_{\tau}\left[\sum_{j=1}^{I} Z_{j \tau}^{S} \sigma f_{k}^{\prime \prime \prime}\left(x_{k \tau}\right) D_{k j} Z_{k \tau-1}^{S} f_{i}^{\prime}\left(e_{i \tau-1}\right) D_{i k}\right]\right] .
$$

The sign of this expression equals the sign of $f_{k}^{\prime \prime \prime}\left(x_{k \tau}\right)$.

It is tempting to think that increased variability would make harvesters more cautious, i.e., escapement levels should increase with greater environmental variability. But this is not necessarily the case. As Proposition 7 shows, increased variability can result in either an increase or a decrease in optimal escapement

\footnotetext{
${ }^{10}$ Proposition 6 relies on a suitably large stock effect at low population levels (Condition 3), though this is not necessary. For arbitrary $c(x)$, Reed [36] shows that provided $x c(x)$ is concave, optimal escapement never decreases with stochasticity. Under that condition, more spread can always induce temporary closures.
} 
levels; a result driven entirely by the shape of the biological growth function. Furthermore, when $c_{i}^{\prime}(s)<0$, there is a tendency for increased variability to increase optimal escapement levels, though not because of some type of precautionary principle. With $c_{i}^{\prime}(s)<0$, greater environmental variability increases the expected value of escapement because the profit function is convex in stock, a point to which we return below (see Proposition 9).

In certain special cases, optimal escapement will be unaffected by changes in variability of random variables, formalized below:

Proposition 8. With an interior solution and assuming Conditions 1 and 2, optimal escapement levels are independent of "small" mean preserving spreads.

Proof. By "small" we allow any mean preserving spread under which the assumption of interior solutions is maintained. Under an interior solution and Conditions 1 and 2, Eq. (15) defines optimal escapement which is independent of random variables.

To this point, we have considered the effects of increased variability on both reserves and escapement levels outside reserves. In the next two propositions we show the effect of increased variability on expected returns from harvest.

Proposition 9. Suppose that an interior solution exists and that $c_{i}^{\prime}(s)<0$. A mean preserving spread on $Z_{i}^{\mu}$ or $Z_{i}^{S}$ will increase annual expected returns for any $i$. Assuming Condition 2, a mean preserving spread on $Z_{i}^{f}$ will increase annual expected returns for any $i$.

Proof. The return from harvest in patch $i$ in period $t$ as a function of initial stock $x_{i t}$ is: $\Pi_{i}\left(x_{i t}\right)=p\left(x_{i t}-e_{i}\right)-\int_{e_{i}}^{x_{i t}} c_{i}(s) \mathrm{d} s$. With $c_{i}^{\prime}(s)<0$ and holding $e_{i}$ constant, we have $\Pi_{i}^{\prime}=p-c_{i}\left(x_{i t}\right)>0$ and $\Pi_{i}^{\prime \prime}=-c_{i}^{\prime}\left(x_{i t}\right)>0$. From Eq. (6), $x_{i t+1}$ is linear in both $Z_{i t}^{\mu}$ and $Z_{i t}^{S}$. Under Condition 2, $x_{i t+1}$ is also linear in $Z_{i t}^{f}$. Because a convex function of a linear function is a convex function, a mean preserving spread on $Z_{i}^{\mu}$ or $Z_{i}^{S}$ (also $Z_{i}^{f}$ assuming Condition 2) will result in an increase in the expected return, holding $e_{i}$ constant. If $e_{i}$ is also allowed to adjust optimally to a change in the distribution, the returns can only increase further.

The result shown in Proposition 9 that larger environmental variability leads to greater expected economic returns from harvest may be counter-intuitive at first glance. The result is driven by the fact that marginal harvest costs are declining in the level of stock $\left(c_{i}^{\prime}(s)<0\right)$. This fact, along with constant price, implies that marginal returns are increasing in stock so that the profit function from harvest in a period is convex in initial stock. The upside gain from a good year more than offsets the downside loss from a bad year leading to increased expected returns with larger variance.

The finding that more variable conditions leads to greater expected economic returns from harvest when all patches are open to harvest can be reversed in the case when a patch is closed to harvest. We given an example of such a case in the next proposition.

Proposition 10. Suppose patch $k$ is closed in periods $\tau$ and $\tau+1$ (whether optimally or not), $0<D_{k k}<1$, all patches $j \neq k$ are at interior solutions for all $t, D_{j k}=0$ for all $j \neq k$ and all $t$, and Conditions 1 and 2 hold. Then $a$ mean preserving spread in $Z_{k}^{f}, Z_{k}^{\mu}$, or $Z_{k}^{S}$ lowers expected returns.

Proof. With $D_{j k}=0$ and interior solutions for all $j \neq k$ for all $t, e_{j t}^{*}$ is independent of conditions in patch $k$, and is thus unaffected by a mean preserving spread in $Z_{k}^{f}, Z_{k}^{\mu}$, or $Z_{k}^{S}$. Because patch $k$ is closed in period $\tau$, and assuming $D_{k k}>0$ and Condition 2, a mean preserving spread in $Z_{k}^{f}, Z_{k}^{\mu}$, or $Z_{k}^{S}$ results in a mean preserving spread in $x_{k \tau+1}$. Because patch $k$ is closed in period $\tau+1, x_{k \tau+1}=e_{k \tau+1}$, so that a mean preserving spread in $Z_{k}^{f}, Z_{k}^{\mu}$, or $Z_{k}^{S}$ results in a mean preserving spread in $e_{k \tau+1}$. By concavity of the growth function, $f_{k}(e)$, a mean preserving spread in $e_{k \tau+1}$ causes a decrease in $E\left(Y_{k \tau+1}\right)$, leading to a decline in $E\left(S_{j \tau+1}\right)$ for all $j \neq k$ for which $D_{k j}>0$. Given Condition 2, this will lead to a decline in $E\left(x_{j \tau+2}\right)$ for all $j \neq k$ for which $D_{k j}>0$. Assuming interior solutions for all patches $j \neq k$, and given Condition 1, a decrease in expected stock leads to a decrease in expected profit from harvest equal to $(p-c)$ times the expected reduction in stock. In addition, a decrease in $E\left(Y_{k \tau+1}\right)$ also leads to a decline in $E\left(S_{k \tau+1}\right)$, and given Condition 2, this will lead to a decline in $E\left(x_{k \tau+2}\right)$, leading to decreased expected value of harvest in periods beyond $\tau+2$. 
Whether an increase in variability of biological parameters leads to increased or decreased expected returns depends to a great extent on whether shocks increase stock variance primarily in closed patches or open patches. In open patches, variance in initial stock contributes to variance in harvest in that period, which leads to an increase in expected returns when marginal costs decline with stock (convex profit function in stock levels). In closed patches, variance in initial stock contributes directly to variance in escapement which feeds into a concave biological growth function, tending to depress expected returns.

\section{Discussion}

Spatial connectivity, heterogeneity, and stochasticity are fundamental attributes of most renewable resources, yet these conditions have been largely neglected in economic models of optimal resource use. In this paper, we extended prior results on the economic theory of optimal renewable resource extraction using a fairly general spatial model under uncertainty. Despite the complexity of the problem, which is spatial, dynamic, and stochastic, we were able to obtain analytical results by exploiting the special structure of the model (state independent control).

As part of this analysis, we characterized when it was economically optimal to close particular areas to harvest (biological reserves). Biologists almost unanimously favor reserves as a natural resource management tool. One argument for reserves is that they help conserve biodiversity, a motivation outside of our analysis in this paper. Some biologists go further, however, and argue for biological reserves on the largely unsubstantiated grounds that they can lead to economic gains. We found that biological reserves can, in fact, boost expected profits and be a part of the first-best economic outcome. This result can occur under a number of realistic bioeconomic conditions and is robust to (even strengthened by) stochasticity within the system. Heterogeneous economic conditions (e.g. high marginal harvest cost in a region) can lead to optimal spatial closures. This result is consistent with theory on optimal harvesting of non-renewable resources [15]. Perhaps more interestingly, even in a spatially homogeneous economic and biological environment, certain patterns of spatial connectivity (e.g. low dispersal to a patch) can generate sufficiently large marginal productivity to make the net marginal value of harvest in that patch negative. In such cases, the patch is optimally closed to harvest. This result can also be obtained as a result of environmental variability or shocks to the dispersal between patches. Patch closures can be either permanent (e.g. in the case of a biological sources and sinks of larval dispersal) or temporary (e.g. in the case of bad draws from the random environment). We found that increasing variability tends to favor temporary closures over establishment of permanent reserves. We also found that increased variability can increase expected economic returns, if the variability primarily affects patches open to harvest. When increased variability primarily affects a patch closed to harvest, though, the concavity of the growth function leads to decreased export of larvae to other patches and tends to decrease expected returns.

Maintaining our focus on harvest closures in particular patches, we also examined how closures affect optimal harvest in open patches outside those closures. When harvest closures are optimal, optimal harvest outside those patches is decreased to take advantage of the high marginal productivity of those patches. This is in direct opposition to the existing models of marine reserve creation that assume complete harvest outside reserves. On the other hand, if reserves are sub-optimally located (i.e., in places in which marginal productivity is low), optimal harvest outside the reserves should actually increase relative to the case in which the patch was not closed. These results underscore an important policy lesson: reserves themselves cannot correct fisheries decline. Economic theory and empirical evidence show that fishermen will adjust effort spatially and rents will dissipate in the absence of other controls [47,23]. The formal treatment of this problem outlined in this paper also provides a platform for more meaningful general analysis of optimal spatial management in the presence of spatial externalities.

We have presented a relatively general spatial, dynamic, and stochastic bioeconomic model and have identified an analytical solution when an interior solution exists and some salient characteristics of the solution when an interior solution does not exist. But this analytical tractability requires several limiting assumptions. An important technical requirement to identify a solution analytically is that the resource owner can measure the harvestable stock prior to harvest without error. The large informational requirements for such fine-tuned management may be prohibitive. If the stock is unknown, the policy design question becomes even more 
difficult. However, this problem could, in principle, be overcome by exploiting the fact that stock dependent harvest costs can reveal information about stock size. In such cases, a spatially heterogeneous tax could be used to achieve the optimal escapement levels [49]. Another limiting assumption is that marginal returns from harvest are independent of the amount harvested. This assumption is standard in the literature and ensures the state independent control property, but may not be realistic in all natural resource contexts. For example, there may be limited inputs (e.g., boats, trained crew members) that would tend to increase marginal costs as harvests expand. Alternatively, downward sloping demand for harvest would also lead to lower decreasing marginal returns as harvest expands. In those cases, shocks that affect stock will lead to harvest smoothing over time, leading to state-dependent escapement levels. Incorporating these extensions is an important next step in the assessment of optimal spatial harvest of renewable resources.

While our results shed new light on an old and increasingly important problem, they also raise new questions about the institutions required to implement them. We have presented the analysis from the perspective of a sole owner with perfect tenure over the entire spatial extent of the resource. Often, however, tenure is divided among many owners. The conclusions drawn here could help guide coordination among multiple resource owners, or allow a regulatory body to design harvesting rules, to achieve the first-best outcome [26]. Coordination among many resource owners may require side-payments, as in the case where an owner owns a single patch for which it is optimal to establish a reserve. Without such coordination, we cannot expect the emergence of efficient spatial resource extraction $[21,26]$.

While we have focused on space as the distinguishing feature across management units, analogies are possible. For example, one could think of age classes as the management unit where transitions occur only to class 1 (via reproduction) and to adjacent, increasing classes (via aging). ${ }^{11}$ Our focus on optimal harvesting with spatial externalities facilitates analysis of current policy questions regarding reserves and their economic implications. The rapid worldwide increase in reserve designation is driven in part by a largely unsubstantiated assumption that creating reserves can increase profit from harvest. We have shown that reserves can indeed increase profits when harvest is efficiently managed outside reserves. But our analysis also emphasizes that careful design, by incorporating economic, rather than just biological reasoning, is essential to their success and efficiency.

\section{Acknowledgment}

The authors acknowledge the National Science Foundation's Biocomplexity program for financial support and UCSB's Flow Fish and Fishing group for intellectual support.

\section{References}

[1] P. Berck, J. Perloff, An open-access fishery with rational expectations, Econometrica 52 (2) (1984) 489-506.

[2] G. Brown, J. Roughgarden, A metapopulation model with private property and a common pool, Ecolog. Econ. 22 (1997) 65-71.

[3] F. Chavez, J. Ryan, S. Lluch-Cota, M. Niquen, From anchovies to sardines and back: multidecadal change in the Pacific Ocean, Science 299 (2003) 217-221.

[4] C. Clark, Profit maximization and the extinction of animal species, J. Polit. Economy 81 (1973) 950-961.

[5] C.W. Clark, Mathematical Bioeconomics, second ed., Wiley, New York, 1990.

[6] C. Clark, G. Munro, The economics of fishing and modern capital theory: a simplified approach, J. Environ. Econ. Manage. 2 (1975) 92-106.

[7] F. Clarke, G. Munro, Coastal states, distant water fishing nations and extended jurisdiction: a principal-agent analysis, Natural Res. Modeling 2 (1) (1987) 81-107.

[8] J. Conrad, The bioeconomics of marine sanctuaries, J. Bioecon. 1 (1999) 205-217.

[9] C. Costello, S. Polasky, A. Solow, Renewable resource management with environmental prediction, Can. J. Econ. 34 (1) (2001) 196-211.

[10] J. Crutchfield, A. Zellner, Economic aspects of the Pacific halibut fishery, Fishery Ind. Res. 1 (1) (1962).

[11] E. Dockner, G. Feischtinger, S. Jorgensen, Tractable classes of nonzero-sum open loop nash differential games: theory and examples, J. Optimization Theory Application 45 (2) (1985) 179-187.

[12] D. Epple, H. Sieg, Estimating equilibrium models of local jurisdictions, J. Polit. Economy 107 (4) (1999) 645-681.

\footnotetext{
${ }^{11}$ We thank Charles Mason for this insight.
} 
[13] I. Ferrara, P. Missios, Transboundary renewable resource management: a dynamic game with differing noncooperative payoffs, Marine Resource Econ. (1996).

[14] M. Fujita, P. Krugman, A. Venables, The Spatial Economy: Cities, Regions, and International Trade, MIT Press, Cambridge, MA, 2001.

[15] G. Gaudet, M. Moreaux, S. Salant, Intertemporal depletion of resource sites by spatially distributed users, The American Economic Review 91 (4) (2001) 1149-1159.

[16] J. Geoghegan, W.B. Gray, Spatial environmental policy, in: H. Folmer, T. Tietenberg (Eds), The International Yearbook of Environmental and Resource Economics 2005/2006, UK. Edward Elgar, Cheltanham, 2005.

[17] H. Gordon, The economic theory of a common property resource: the fishery, J. Polit. Economy 62 (1954) 124-142.

[18] R.Q. Grafton, T. Kompas, D. Lindenmayer, Marine reserves with ecological uncertainty, Bull. Math. Biology 67 (2005) $957-971$.

[19] Q. Grafton, D. Squires, J. Kirkley, Private property rights and crises in world fisheries: turning the tide?, Contemporary Econ. Pol. 14 (4) (1996) 90-99.

[20] R. Hannesson, Marine reserves: what would they accomplish?, Marine Resource Econ. 13 (1998) 159-170.

[21] Z. Hansen, G. Libecap, Small farms, externalities, and the dust bowl of the 1930s, J. Polit. Econ. 112 (3) (2004) $665-694$.

[22] A. Hastings, L.W. Botsford, Equivalence in yield from marine reserves and traditional fisheries management, Science 284 (1999) $1537-1538$.

[23] D. Holland, Spatial fishery rights and marine zoning: a discussion with reference to management of marine resources in New England, Marine Resource Econ. 19 (2004) 21-40.

[24] D. Holland, R. Brazee, Marine reserves for fisheries management, Marine Resource Econ. 11 (1996) $157-171$.

[25] J. Jackson, M. Kirby, W. Berger, K. Bjorndal, L. Botsford, B. Bourque, R. Bradbury, R. Cooke, J. Erlandson, J. Estes, T. Hughes, S. Kidwell, C. Lange, H. Lenihan, J. Pandolfi, C. Peterson, R. Steneck, M. Tegner, R. Warner, Historical overfishing and the recent collapse of coastal ecosystems, Science 293 (2001) 629-637.

[26] Janmaat, J. Sharing clams: tragedy of an incomplete commons, J. Environ. Econ. Manage. 49 (1) (2005) $26-51$.

[27] R. Johnson, G. Libecap, Contracting problems and regulation: the case of the fishery, Amer. Econ. Rev. 72 (5) (1982) $1005-1022$.

[28] C. Kolstad, Hotelling rents in hotelling space: product differentiation in exhaustible resource markets, J. Environ. Econ. Manage. 26 (1994) $163-180$.

[29] J.-J. Laffont, The Economics of Uncertainty and Information, MIT Press, Cambridge, MA, 1989.

[30] P. Missios, C. Plourde, Transboundary renewable resource management and conservation motives, Marine Resource Econ. 12 (1) (1997) 29-36.

[31] G. Munro, The optimal management of transboundary renewable resources, Can. J. Econ./Revue canadienne d'Economique 12 (3) (1979) 355-376.

[32] G. Munro, The management of shared fishery resources under extended jurisdiction, Marine Resource Econ. 3 (4) (1987) $271-296$.

[33] R. Myers, B. Worm, Rapid worldwide depletion of predatory fish communities, Nature 423 (2003) $280-283$.

[34] T. Naito, S. Polasky, Analysis of a highly migratory fish stocks fishery: a game theoretic approach, Marine Resource Econ. (1997).

[35] M. Neubert, Marine reserves and optimal harvesting, Ecolog. Lett. 6 (2003) 843-849.

[36] W. Reed, Optimal escapement levels in stochastic and deterministic harvesting models, J. Environ. Econ. Manage. 6 (1979) $350-363$.

[37] J. Roughgarden, F. Smith, Why fisheries collapse and what to do about it, Proceed. Nat. Acad. Sci. 93 (1996) $5078-5083$.

[38] J. Sanchirico, U. Malvadkar, A. Hastings, J. Wilen, When are no-take zones an economically optimal fishery management strategy?, Ecol. Applications 16 (5) (2006) 1643-1659.

[39] J. Sanchirico, J. Wilen, Bioeconomics of spatial exploitation in a patchy environment, J. Environ. Econ. Manage. 37 (1999) $129-150$.

[40] J. Sanchirico, J. Wilen, A bioeconomic model of marine reserve creation, J. Environ. Econ. Manage. 42 (2001) $257-276$.

[41] J. Sanchirico, J. Wilen, Optimal spatial management of renewable resources: matching policy scope to ecosystem scale, J. Environ. Econ. Manage. 50 (1) (2005) 23-46.

[42] A. Scott, The fishery: the objectives of sole ownership, J. Polit. Economy 63 (1955) 116-124.

[43] G. Sethi, C. Costello, A. Fisher, M. Hanemann, L. Karp, Fishery management under multiple uncertainty, J. Environ. Econ. Manage. 50 (2) (2004) 300-318.

[44] V. Smith, Economics of production from natural resources, Amer. Econ. Rev. 58 (1968) 409-431.

[45] V. Smith, On models of commercial fishing, J. Polit. Economy 77 (1969) 181-198.

[46] M. Smith, J. Wilen, Economic impacts of marine reserves: the importance of spatial behavior, J. Environ. Econ. Manage. 46 (2) (2003) 183-206.

[47] M. Smith, J. Zhang, F. Coleman, Effectiveness of marine reserves for large-scale fisheries management, Can. J. Fisheries Aquatic Sci. 63 (2006) 153-164.

[48] D. Tilman, P. Kareiva, Spatial Ecology: The Role of Space in Population Dynamics and Interspecific Interactions, Princeton University Press, Princeton, NJ, 1997.

[49] M. Weitzman, Landing fees vs harvest quotas with uncertain fish stocks, J. Environ. Econ. Manage. 43 (2) (2002) $325-338$.

[50] J. Wilen, Renewable resource economists and policy: what differences have we made?, J. Environ. Econ. Manage. 39 (2000) 306-327.

[51] World Database on Protected Areas 〈http://sea.unep-wcmc.org/wdbpa/, 2005.

[52] B. Worm, E. Barbier, N. Beaumont, J. Duffy, C. Folke, B. Halpern, J. Jackson, H. Lotze, F. Micheli, S. Palumbi, E. Sala, K. Selkoe, J. Stachowicz, R. Watson, Impacts of biodiversity loss on ocean ecosystem services, Science 314 (2006) 787-790. 